\title{
Asymptomatic malaria and anaemia among pregnant women during high and low malaria transmission seasons in Burkina Faso: household-based cross-sectional surveys in Burkina Faso, 2013 and 2017
}

Toussaint Rouamba ${ }^{1,2^{*}+} \mathbb{0}$, Sékou Samadoulougou ${ }^{3,4+}$, Mady Ouédraogo ${ }^{2,5}$, Hervé Hien ${ }^{6,7}$, Halidou Tinto ${ }^{1}$ and Fati Kirakoya-Samadoulougou ${ }^{2}$

\begin{abstract}
Background: Malaria in endemic countries is often asymptomatic during pregnancy, but it has substantial consequences for both the mother and her unborn baby. During pregnancy, anaemia is an important consequence of malaria infection. In Burkina Faso, the intensity of malaria varies according to the season, albeit the prevalence of malaria and anaemia as well as their risk factors, during high and low malaria transmission seasons is underexplored at the household level.

Methods: Data of 1751 pregnant women from October 2013 to March 2014 and 1931 pregnant women from April 2017 to June 2017 were drawn from two cross-sectional household surveys conducted in 24 health districts of Burkina Faso. Pregnant women were tested for malaria in their household after consenting. Asymptomatic carriage was defined as a positive result from malaria rapid diagnostic tests in the absence of clinical symptoms of malaria. Anaemia was defined as haemoglobin level less than $11 \mathrm{~g} / \mathrm{dL}$ in the first and third trimester and less than $10.5 \mathrm{~g} / \mathrm{dL}$ in the second trimester of pregnancy.

Results: Prevalence of asymptomatic malaria in pregnancy was estimated at $23.9 \%$ (95\% Cl 20.2-28.0) during the high transmission season (October-November) in 2013. During the low transmission season, it was $12.7 \%(95 \% \mathrm{Cl}$ 10.9-14.7) between December and March in 2013-2014 and halved (6.4\%; 95\% Cl 5.3-7.6) between April and June 2017. Anaemia prevalence was estimated at 59.4\% (95\% Cl 54.8-63.8) during the high transmission season in 2013. During the low transmission season, it was 50.6\% (95\% Cl 47.7-53.4) between December and March 2013-2014 and 65.0\% (95\% Cl 62.8-67.2) between April and June, 2017.
\end{abstract}

*Correspondence: rouambatoussaint@gmail.com

†¥Rouamba Toussaint and Samadoulougou Sékou contributed equally to this work

${ }^{1}$ Clinical Research Unit of Nanoro, Institut de Recherche en Sciences de La Santé, Centre National de La Recherche Scientifique Et Technologique, 42, Avenue Kumda-Yoore, BP 218 Ouagadougou CMS 11, Ouagadougou, Burkina Faso

Full list of author information is available at the end of the article

(c) The Author(s) 2021. This article is licensed under a Creative Commons Attribution 4.0 International License, which permits use, sharing, adaptation, distribution and reproduction in any medium or format, as long as you give appropriate credit to the original author(s) and the source, provide a link to the Creative Commons licence, and indicate if changes were made. The images or other third party material in this article are included in the article's Creative Commons licence, unless indicated otherwise in a credit line to the material. If material is not included in the article's Creative Commons licence and your intended use is not permitted by statutory regulation or exceeds the permitted use, you will need to obtain permission directly from the copyright holder. To view a copy of this licence, visit http://creativeco mmons.org/licenses/by/4.0/. The Creative Commons Public Domain Dedication waiver (http://creativecommons.org/publicdomain/ zero/1.0/) applies to the data made available in this article, unless otherwise stated in a credit line to the data. 
Conclusion: This study revealed that the prevalence of malaria asymptomatic carriage and anaemia among pregnant women at the community level remain high throughout the year. Thus, more efforts are needed to increase prevention measures such as IPTp-SP coverage in order to reduce anaemia and contribute to preventing low birth weight and poor pregnancy outcomes.

Keywords: Asymptomatic carriage, Plasmodium, Haemoglobin, Community, Pregnant, Health district

\section{Background}

Every year, about $25 \%$ of maternal deaths in hyperendemic malaria regions are due to malaria infection in pregnancy (MiP) [1]. In sub-Saharan African (SSA) countries, MiP is often asymptomatic, which is one of the main challenges in controlling MiP. Indeed, asymptomatic carriage has substantial health consequences for the mother, her unborn baby, and her future newborn. Adverse consequences of MiP for both the mother and her unborn baby include fetal loss [2-4], intrauterine growth retardation $[5,6]$, preterm delivery $[5,6]$, low birth weight [5-8], congenital malaria [3, 9], perinatal mortality $[2,6]$, and increased risks of maternal anaemia [6, 7]. Several studies reported a high prevalence of asymptomatic MiP (ranging from 21 to 58.4\%) in SSA countries [10-14], including Burkina Faso, and this represents a major public health problem since pregnant women living in these communities are not aware they are asymptomatic carriers of malaria parasites.

To protect women from asymptomatic MiP and its consequences, the World Health Organization (WHO) recommends combined intervention, including intermittent preventive treatment during pregnancy with sulfadoxine-pyrimethamine (IPTp-SP) and iron + folic acid supplementation during antenatal care (ANC) [15]. Albeit, the effectiveness of IPTp-SP seemed to be compromised by the spread of resistance to SP in most African countries [16, 17], several studies reported that the IPTp-SP continues to reduce the incidence of malaria parasites carriage and the malaria-attributable adverse pregnancy outcomes namely, low birthweight, and maternal anaemia [18-22]. Even in areas with excellent SP sensitivity, such as in many parts of West Africa, there is still a high prevalence of placental infections in women receiving less than three doses of SP, particularly during the peak of malaria transmission season [23].

In Burkina Faso, around three-quarters of the population use self-medication or traditional therapy when signs of malaria are suspected [24]. By implication, around one-quarter of the population attends a clinic when they feel ill or due to scheduled visits (namely ANC), and are treated when there is confirmed malaria. Consequently, asymptomatic MiP cases and anaemia remain untreated. The prevalence of asymptomatic MiP among women attending routine ANC was estimated at about $19-51 \%$ based on malaria rapid diagnostic tests (RDTs) [25-28], whereas anaemia prevalence was estimated at around $60 \%[27,28]$. There are only a few community-based published studies that have estimated the prevalence of MiP [29] at the household level; in this case, conducted in Nanoro and nested within a cluster-randomized controlled trial. In Burkina Faso, the majority of published data on the subject have been obtained in healthcare settings (i.e., in health facilities). It is, therefore, important to have better insight into asymptomatic MiP and its corollary anaemia, at the community level. This will provide useful indicators to guide decision-making regarding control strategies and to optimize interventions in the context of resource constraints.

This study, aimed to estimate the prevalence of asymptomatic carriage of malaria parasites and anaemia among pregnant women in their community through a household survey during low and high malaria transmission seasons in Burkina Faso. The study also aimed to identify the potential factors associated with asymptomatic carriage and anaemia among pregnant women surveyed at their household.

\section{Methods}

Study population, design and sampling procedures

This study analysed data collected from 24 health districts located in six regions of Burkina Faso (Boucle de Mouhoun, Center-East, Center-North, Center-West, North, and South-West). The population consisted of pregnant women who were present in the household during the survey visit and who consented to participate in the study. The main project, entitled "Impact Evaluation for Health Performance-Based Financing in Burkina Faso", was designed to assess the impact of a performance-based financing strategy on the quality of healthcare delivery [30]. The latter aimed to strengthen the public sector and enhance general health, including health indicators, with a particular focus on maternal and child health. This impact assessment was performed through health facility- and household-based surveys and consisted of cross-sectional studies carried out in 2013/2014 (prior to project implementation) and 2017 (after the project implementation), in which the health districts were non-randomly selected. The study protocol, 
including the survey design, are published elsewhere [30]. Briefly, a two-stage stratified cluster sampling was carried-out where the household was the sampling unit. The first stage of the sampling consisted to randomly select a village within each health facility, and then create a sample frame that included all the households, which had at least one pregnant woman or a woman who delivered in the last two years. The second stage consisted to perform a systematic sampling of 15 households within each frame. In total 7844 and 8182 households were surveyed respectively in year 2013/2014 and 2017.

Data on sociodemographics, health behaviour, and economic factors as well as on the health conditions of pregnant women were collected for each selected household. These data were collected using a computerassisted personal interview (CAPI) household questionnaire. From these two cross-sectional household surveys, data on 1751 and 1931 pregnant women were drawn in 2013/2014 (from October 2013 to March 2014) and 2017 (From April to June 2017). To provide a snapshot of the prevalence, the timeline of data collection in the field was for a full year of malaria transmission (i.e., for low and high transmission). The first data collection was conducted between October 2013 and March 2014, and the second one occurred from April to June 2017.

\section{Malaria diagnosis and estimation of haemoglobin}

During the household-based surveys, blood samples were taken by finger prick to detect the presence of the malaria parasite and to measure haemoglobin level. In both surveys, malaria was confirmed by serology using RDT SD Bioline, which detects histidine-rich protein II (HRP-II). HRP-II-based diagnostic test accuracy with microscopy as reference test for detection of malaria in asymptomatic pregnant women in Burkina Faso was 96.4\% (95\% CI 91-99) and 73.9 (95\% CI 68-79), respectively, for sensitivity and specificity [31].

The haemoglobin level was measured by the haematological acid technique using a haemoglobinometer $\left(\mathrm{HemoCue}^{\circledR}\right)$. During the field surveys, quality controls were carried out on randomly selected malaria-positive samples (microscopy performed on thick blood smears). Similarly, quality controls were performed on haemoglobin measures using an automated haematology analyzer.

Since the definition of anaemia in pregnancy varies according to the trimester of pregnancy to reflect changes in blood volume, in this study the pregnant women was categorized as anemic if the haemoglobin level $(\mathrm{Hb})$ was $<11 \mathrm{~g} / \mathrm{dL}$ in the first trimester, $<10.5 \mathrm{~g} / \mathrm{dL}$ in the second trimester and $<11 \mathrm{~g} / \mathrm{dL}$ in the third trimester [32].

\section{Study variables}

This study assessed two main binary outcomes: asymptomatic carriage of malaria parasites (Yes or No) and anaemia (Yes or No) according to the definition mentioned above [32]. The explanatory variables were based mainly on individual- and household-level characteristics. The selection of these explanatory variables was based on epidemiological interest as well as on previous studies that have shown the relationship between potential risk factors and MiP (or anaemia) [10, 25-27, 33, 34]. These explanatory variables for pregnant women were age $(<20,20-30$, and $>30$ years old), parity [primigravida, secundigravida, and multigravida $(\geq 3)$ ], and gestational age [first trimester ( $\leq 3$ months), and second (between 3-6 months) or third trimester ( $\geq 7$ months)]. It is noticeable that during household surveys the gestational age was determined by recall of last menstrual cycle date. In addition, if the woman was already attended a health facility for her antenatal care, the enumerators checked from antenatal cards or other relevant documents.

Other variables included the mother's education level (no education and educated), ownership of insecticidetreated nets in the household (No and $\geq 1$ ), the household's standard of living (very poor, poor, moderate rich, rich, and very rich), and place of residence (urban and rural). To analyze malaria transmission among pregnant women, the study period was cut into two seasons: a high transmission season from July to November and a low transmission season from December to June [35]. It is noticeable that in this study, haemoglobin level was not considered as predictor of malaria because, in this present study, anaemia was already considered as a main consequence of MiP.

\section{Statistical analysis}

The prevalence of asymptomatic carriage was estimated based on the proportion of pregnant women who tested positive with the malaria RDT. Likewise, the prevalence of anaemia was determined as the proportion of pregnant women with a haemoglobin level less than $11 \mathrm{~g} /$ $\mathrm{dL}$ in the first and third trimester, and $<10.5 \mathrm{~g} / \mathrm{dL}$ in the second trimester among those who underwent haematological testing. Descriptive statistics were used to document asymptomatic carriage of malaria parasites, anaemia, and sociodemographic characteristics of pregnant women. Cross-tabulations were performed separately for each time point of the survey.

For each main outcome (i.e., asymptomatic carriage and anaemia), both univariate and multivariable modified Poisson regressions with generalized estimating equations (GEE) were performed. The selection of variables for multivariable analysis was based on epidemiological interest and based on previous studies that 
Table 1 Sociodemographic characteristics of pregnant women surveyed at the household level in Burkina Faso, 2013 and 2017

\begin{tabular}{|c|c|c|c|}
\hline \multirow[t]{2}{*}{ Characteristics } & \multicolumn{2}{|l|}{ Year } & \multirow[t]{2}{*}{$p$ value } \\
\hline & $\begin{array}{l}2013- \\
2014\end{array}$ & 2017 & \\
\hline Total (number) & 1751 & 1931 & \\
\hline Age, $n(\%)$ & & & $<0.001^{\mathrm{a}}$ \\
\hline$\geq 30$ & $480(27.4)$ & $655(33.9)$ & \\
\hline $20-30$ & $883(50.4)$ & $982(50.9)$ & \\
\hline$\leq 20$ & $388(22.2)$ & $294(15.2)$ & \\
\hline Education, n(\%) & & & $<0.001^{a}$ \\
\hline No education & $1737(99.2)$ & $\begin{array}{l}1849 \\
(95.8)\end{array}$ & \\
\hline Educated & $14(0.8)$ & $82(4.2)$ & \\
\hline \multicolumn{2}{|c|}{ Household socioeconomic status, n(\%) } & & 0.66 \\
\hline Poorest & $310(17.7)$ & $349(18.1)$ & \\
\hline Poor & $371(21.2)$ & $374(19.4)$ & \\
\hline Middle quintile & $358(20.4)$ & $388(20.1)$ & \\
\hline Rich & $344(19.6)$ & $400(20.7)$ & \\
\hline Richest & $368(21.0)$ & $420(21.8)$ & \\
\hline Place of residence, n(\%) & & & 0.41 \\
\hline Rural & $1624(92.7)$ & $\begin{array}{l}1776 \\
(92.0)\end{array}$ & \\
\hline Urban & $127(7.3)$ & $155(8.0)$ & \\
\hline Region, n(\%) & & & 0.74 \\
\hline Centre-North & $412(23.5)$ & $443(22.9)$ & \\
\hline Boucle de Mouhoun & $339(19.4)$ & $356(18.4)$ & \\
\hline Centre-East & $218(12.5)$ & $270(14.0)$ & \\
\hline Centre-West & $292(16.7)$ & $314(16.3)$ & \\
\hline North & $380(21.7)$ & $416(21.5)$ & \\
\hline South-West & $110(6.3)$ & $132(6.8)$ & \\
\hline Parity, n(\%) & & & $<0.001^{a}$ \\
\hline Multigravida & $1067(60.9)$ & $\begin{array}{l}1396 \\
(72.3)\end{array}$ & \\
\hline Secundigravida & $364(20.8)$ & $325(16.8)$ & \\
\hline Primigravida & $320(18.3)$ & $210(10.9)$ & \\
\hline Trimester of pregnancy, n(\%) & & & $0.016^{\mathrm{a}}$ \\
\hline First & $415(23.7)$ & $450(23.3)$ & \\
\hline Second & $753(43.0)$ & $755(39.1)$ & \\
\hline Third & $583(33.3)$ & $726(37.6)$ & \\
\hline Insecticide-treated nets, n(\%) & & & 0.82 \\
\hline At least one & $1690(96.5)$ & $\begin{array}{c}1860 \\
(96.3)\end{array}$ & \\
\hline No insecticide-treated nets & $61(3.5)$ & $71(3.7)$ & \\
\hline
\end{tabular}

${ }^{a}$ significant at the 0.05 level

exhibited links between potential risk factors and the study outcomes. The modified Poisson regression with GEE were used to estimate unadjusted and adjusted prevalence ratios (Adj. PRs) with 95\% confidence intervals (CIs), and two-tailed $\mathrm{p}$ values $<0.05$ were considered as statistically significant. The generalized variance-inflation factors were computed to check for multi collinearity between the explanatory variables [36].

All statistical analyses were performed with $\mathrm{R}$ statistical software ( $\mathrm{R}$ Development Core Team, R Foundation for Statistical Computing, Vienna, Austria), and regression models were fitted using the "geepack" package.

\section{Results \\ Population characteristics}

A total of 7844 and 8182 households were included for the 2013/2014 and 2017 surveys, respectively. Of the households included in the main study, $21.8 \%$ $(1709 / 7844)$ and $23.4 \%(1916 / 8182)$ had at least one pregnant woman for the 2013/2014 and 2017 surveys, respectively. The sociodemographic characteristics of the pregnant women for each survey are summarized in Table 1 . The characteristics of the study population followed the same distribution, with the exception of age, parity, education, trimester of pregnancy, and malaria transmission season. In fact, about half of the women were between 20 and 30 years old, and most did not attend a formal school (97.4\%). About 23.5\% of pregnant women were survey during their first trimester of pregnancy. The majority of women lived in rural areas $(92.3 \%)$ and were multigravidae (66.9\%). Additionally, $100 \%$ of the women surveyed in 2017 were investigated during the low transmission season (between April and June). Regarding the 2013/2014 survey, 70.2\% were investigated during the high transmission season (between October and November), whereas $29.8 \%$ were interviewed during the low transmission season (between December and mid-March). More than threequarters of the women were investigated in the second or third trimester of pregnancy.

\section{Prevalence of asymptomatic carriage of malaria parasites} among pregnant women surveyed at the household level The prevalence of asymptomatic carriage of malaria parasites and $95 \%$ CIs by gravidity and according to malaria transmission season is presented in the Fig. 1. The prevalence of asymptomatic carriage of the malaria parasites was estimated at $15.9 \%$ (95\% CI 14.2-17.7) in $2013 / 2014$. This prevalence was estimated at $12.7 \%$ (95\% CI 10.9-14.7) for the low transmission season and 23.9\% (95\% CI 20.2-28.0) for the high transmission season. In 2017, between April and June (low transmission season), the prevalence of asymptomatic carriage of the malaria parasites was estimated at $6.4 \%$ (95\% CI 5.3-7.6). The prevalence of asymptomatic-carriage was two-fold higher during the high season compared with low season. During the high season the prevalence of asymptomatic 


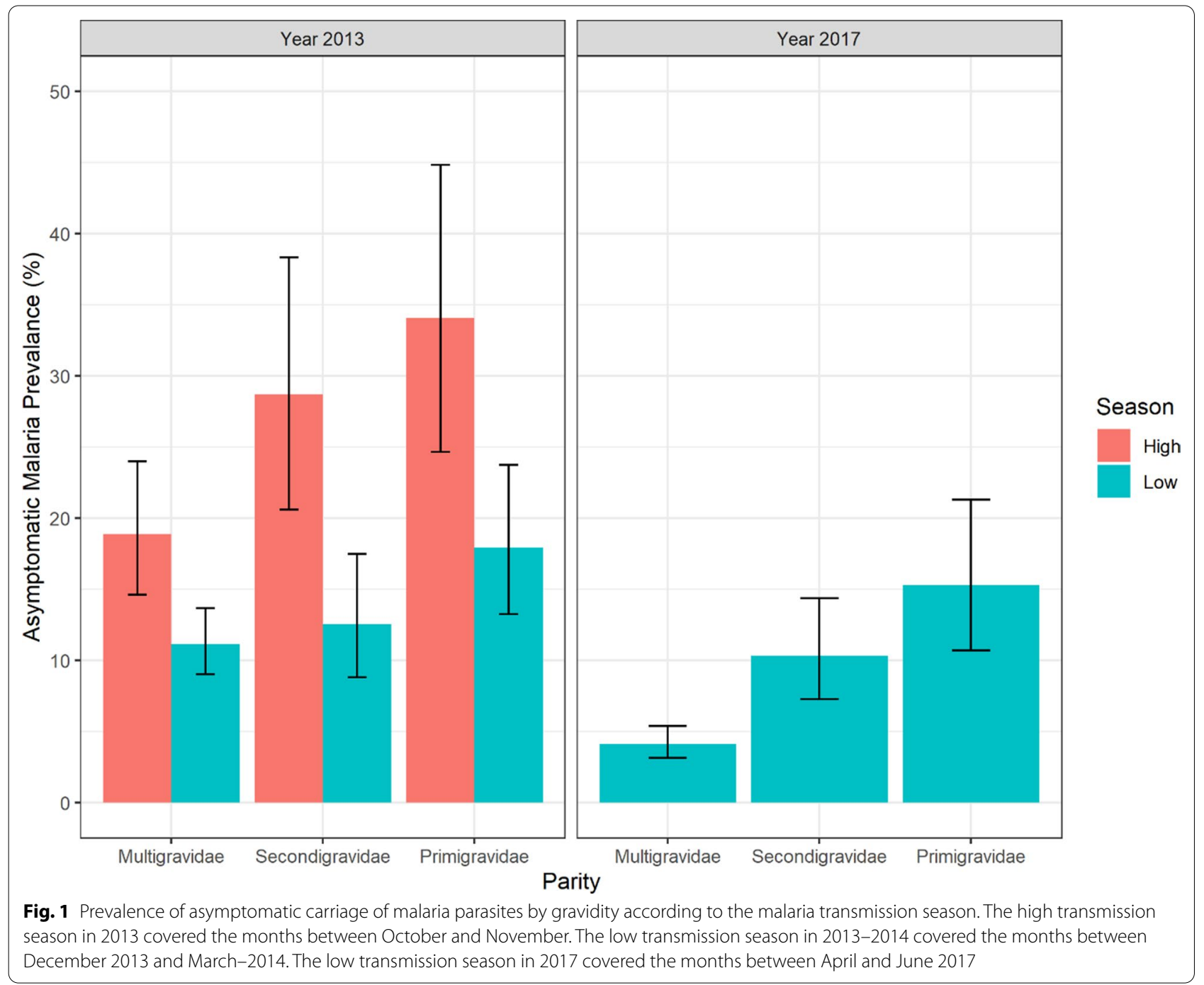

carriage of malaria parasites was estimated at $18.9 \%(95 \%$ CI 14.6-24.0), $28.7 \%$ (95\% CI 20.6-38.3), and 34.1\% (95\% CI 24.7-44.8) respectively for multigravidae, secondigravidae and primigravidae.

\section{Factors associated with asymptomatic carriage} among pregnant women surveyed at the household level The results of multivariable analyses to identify potential factors associated with asymptomatic carriage are summarized in Tables 2 and 3 for 2013/2014 and 2017, respectively. The results show previously identified risk factors for MiP, namely young maternal age, primigravidae, the first trimester of pregnancy, and the high malaria transmission season. Regarding the transmission season, the prevalence of asymptomatic carriage of malaria parasites was 1.83 (95\% CI 1.47-2.29) times higher during the high transmission season compared to that of the low transmission season. During the year 2017, consisting only of women recruited during the low transmission season, i.e. between April 2017 and June, the prevalence of asymptomatic carriage halved and was estimated at 6.4\% (95\% CI 5.3-7.6). There was no statistical association between asymptomatic carriage of malaria parasites and ownership of insecticide-treated nets, household socioeconomic status, education, nor place of residence.

\section{Prevalence of anaemia among pregnant women surveyed at the household level}

In 2013/2014, the mean haemoglobin was estimated at $10.5(\mathrm{SD}=1.6) \mathrm{g} / \mathrm{dL}$ and prevalence of anaemia was $35.9 \%$ (95\% CI 33.6-38.2). In year 2017, the mean haemoglobin was $10.2(\mathrm{SD}=1.4)$ and prevalence of anaemia was $46.6 \%$ (95\% CI 44.3-48.9). The prevalence of anaemia $95 \%$ CIs by trimester of pregnancy and according to 
Table 2 Risk factors associated with asymptomatic carriage of malaria parasites among pregnant women surveyed at the household level in Burkina Faso in 2013/2014

\begin{tabular}{|c|c|c|c|c|c|c|}
\hline \multirow[t]{2}{*}{ Potential factors } & \multirow[t]{2}{*}{$\mathbf{N}$} & \multirow[t]{2}{*}{ MiP cases } & \multicolumn{2}{|c|}{ Univariate analysis } & \multicolumn{2}{|c|}{ Multivariable analysis } \\
\hline & & & PR $(95 \% \mathrm{Cl})$ & $\mathrm{p}$ & Adj. PR (95\% Cl) & $\mathrm{p}$ \\
\hline Age & & & & $<0.001^{\mathrm{a}}$ & & $<0.001^{a}$ \\
\hline$\geq 30$ & 468 & 59 & 1 & & 1 & \\
\hline $20-30$ & 380 & 122 & $1.13(0.84-1.51)$ & & $1.07(0.80-1.38)$ & \\
\hline$\leq 20$ & 859 & 90 & $1.88(1.39-2.53)$ & & $1.57(1.04-2.38)$ & \\
\hline Trimester of pregnancy & & & & 0.08 & & 0.13 \\
\hline First & 404 & 77 & 1 & & & \\
\hline Second & 731 & 115 & $0.83(0.64-1.07)$ & & $0.88(0.68-1.14)$ & \\
\hline Third & 573 & 79 & $0.72(0.54-0.96)$ & & $0.77(0.58-1.02)$ & \\
\hline Parity & & & & $<0.001^{\mathrm{a}}$ & & 0.63 \\
\hline Multigravida & 1039 & 138 & 1 & & 1 & \\
\hline Secundigravida & 314 & 62 & $1.31(1.00-1.73)$ & & $1.10(0.80-1.49)$ & \\
\hline Primigravida & 354 & 71 & $1.70(1.32-2.20)$ & & $1.21(0.83-1.76)$ & \\
\hline Insecticide-treated nets & & & & 0.99 & & 0.88 \\
\hline At least one & 1650 & 262 & 1 & & 1 & \\
\hline No insecticide-treated nets & 57 & 9 & $0.99(0.54-1.83)$ & & $0.89(0.50-1.61)$ & \\
\hline Education & & & & 0.56 & & 0.86 \\
\hline No education & 1693 & 268 & 1 & & 1 & \\
\hline Educated & 14 & 3 & $1.35(0.49-3.71)$ & & $1.24(0.46-3.33)$ & \\
\hline Household socioeconomic & & & & 0.90 & & 0.85 \\
\hline Middle quintile & 352 & 52 & 1 & & 1 & \\
\hline Poorest & 300 & 51 & $1.15(0.81-1.64)$ & & $1.10(0.78-1.55)$ & \\
\hline Poor & 364 & 57 & $1.06(0.75-1.49)$ & & $1.05(0.75-1.48)$ & \\
\hline Rich & 338 & 51 & $1.02(0.71-1.45)$ & & $1.05(0.74-1.49)$ & \\
\hline Richest & 354 & 60 & $1.14(0.81-1.61)$ & & $1.18(0.84-1.65)$ & \\
\hline Place of residence & & & & 0.84 & & 0.91 \\
\hline Rural & 1586 & 251 & 1 & & 1 & \\
\hline Urban & 120 & 20 & $1.05(0.69-1.58)$ & & $0.96(0.64-1.43)$ & \\
\hline Malaria season & & & & $<0.001^{\mathrm{a}}$ & & $<0.001^{a}$ \\
\hline Low season & 1222 & 155 & 1 & & 1 & \\
\hline High season & 485 & 116 & $1.89(1.52-2.34)$ & & $1.85(1.49-2.29)$ & \\
\hline
\end{tabular}

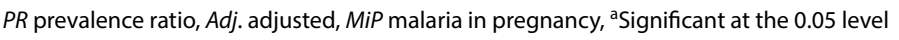

malaria transmission season is presented in the Fig. 2. During the low transmission season of 2014 (i.e., December to March), the prevalence of anaemia was estimated at $32.7 \%$ (95\% CI 30.1-35.5). During the high transmission season of 2013 (i.e., October to November), the prevalence of anaemia was $43.7 \%$ (95\% CI 39.3-48.3). During the high season the prevalence of anaemia was estimated at 59.4\% (95\% CI 50.7-67.6), 50.0\% (95\% CI 43.3-56.7), and 58.3\% (95\% CI 50.6-65.6), respectively at first, second and third trimester of pregnancy.

\section{Risk factors associated with anaemia among pregnant women surveyed at the household level}

In general, as shown in Tables 4 and 5 , the prevalence of anaemia was higher in pregnant women with malaria than in those who had no malaria infection. Likewise, the prevalence of anaemia was lower among pregnant women with the richest household socioeconomic status. After adjustment, we observed a lower prevalence of anaemia among women in the first trimester of pregnancy, which was more noticeable for the year 2017 (Table 5). Compared with non-infected pregnant women, asymptomatic carriage of malaria parasites was associated with a higher prevalence of anaemia (1.63; 95\% CI 1.43-1.86). The results indicated that lower (poorest) 
Table 3 Risk factors associated with asymptomatic carriage among pregnant women surveyed at the household level in Burkina Faso in 2017

\begin{tabular}{|c|c|c|c|c|c|c|}
\hline \multirow[t]{2}{*}{ Potential factors } & \multirow[t]{2}{*}{$\mathbf{N}$} & \multirow[t]{2}{*}{ MiP cases } & \multicolumn{2}{|c|}{ Univariate analysis } & \multicolumn{2}{|c|}{ Multivariable analysis } \\
\hline & & & PR $(95 \% \mathrm{Cl})$ & $\mathrm{p}$ & Adj. PR (95\% Cl) & $\mathrm{p}$ \\
\hline Age & & & & $<0.001^{\mathrm{a}}$ & & $<0.001^{\circ}$ \\
\hline$\geq 30$ & 623 & 18 & 1 & & 1 & \\
\hline $20-30$ & 275 & 41 & $5.16(3.02-8.82)$ & & $1.71(1.01-2.91)$ & \\
\hline$\leq 20$ & 933 & 58 & $2.15(1.28-3.62)$ & & $2.73(1.32-5.67)$ & \\
\hline Trimester of pregnancy & & & & $<0.001^{\mathrm{a}}$ & & $<0.001^{\circ}$ \\
\hline First & 426 & 21 & 1 & & 1 & \\
\hline Second & 709 & 53 & $0.74(0.5-1.09)$ & & $0.71(0.49-1.03)$ & \\
\hline Third & 697 & 43 & $0.30(0.18-0.50)$ & & $0.28(0.17-0.47)$ & \\
\hline Parity & & & & $<0.001^{\mathrm{a}}$ & & 0.052 \\
\hline Multigravida & 1325 & 55 & 1 & & 1 & \\
\hline Secundigravida & 310 & 32 & $2.49(1.64-3.78)$ & & $1.75(1.07-2.87)$ & \\
\hline Primigravida & 196 & 30 & $3.69(2.43-5.61)$ & & $2.07(1.10-3.90)$ & 0.10 \\
\hline Insecticide-treated nets & & & & $0.020^{\mathrm{a}}$ & & \\
\hline At least one & 1762 & 108 & 1 & & 1 & \\
\hline No insecticide-treated nets & 69 & 9 & $2.13(1.13-4.02)$ & & $1.58(0.80-3.11)$ & \\
\hline Education & & & & 0.58 & & 0.81 \\
\hline No education & 1755 & 111 & 1 & & 1 & \\
\hline Educated & 76 & 6 & $1.25(0.57-2.75)$ & & $1.09(0.49-2.4)$ & \\
\hline Household socioeconomic & & & & 0.14 & & 0.59 \\
\hline Middle quintile & 360 & 23 & 1 & & 1 & \\
\hline Poorest & 334 & 31 & $1.45(0.87-2.44)$ & & $1.28(0.76-2.15)$ & \\
\hline Poor & 363 & 22 & $0.95(0.54-1.67)$ & & $0.93(0.53-1.62)$ & \\
\hline Rich & 375 & 17 & $0.71(0.39-1.31)$ & & $0.83(0.46-1.52)$ & \\
\hline Richest & 399 & 24 & $0.94(0.54-1.64)$ & & $0.92(0.55-1.56)$ & \\
\hline Place of residence & & & & 0.10 & & 0.15 \\
\hline Rural & 1685 & 103 & 1 & & 1 & \\
\hline Urban & 146 & 14 & $1.57(0.92-2.67)$ & & $1.46(0.87-2.44)$ & \\
\hline
\end{tabular}

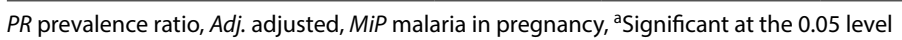

socioeconomic status (Adj. PR: 1.20; 95\% CI 1.03-1.39) and high transmission season (Adj. PR: 1.30; 95\% CI 1.13-1.5) were significantly associated with anaemia. The prevalence of anaemia did not differ according to parity, ownership of insecticide-treated nets, education, nor place of residence.

\section{Discussion}

The presence of malaria and anaemia in pregnancy, regardless of the gestational stage, are potentially harmful to both the fetus and mother as well as to the family and community $[1,2,5-8,37,38]$. This study provides insights into the extent of asymptomatic MiP and its corollary, anaemia, at the community level (i.e., pregnant women surveyed in their own family home) throughout different malaria transmission periods of the year in Burkina Faso.
The study findings show that the prevalence of asymptomatic MiP and anaemia at the household level was high. In this present study, the MiP prevalence was higher among young women, increased significantly during the high transmission season and increased the risk of maternal anaemia. For the survey conducted in 2017, the risk of MiP was higher during the first trimester of pregnancy.

The prevalence of asymptomatic carriage of malaria parasites found in this household-based study was lower compared with the estimated prevalence reported in previous studies, where it was reported to range from 19 to $51 \%$, among pregnant women attending health facilities as part of their ANC in Burkina Faso [25-28]. However, the overall aggregate prevalence of asymptomatic MiP $(11.0 \%)$ reported in our study corroborates the results (12.2\%) from the COSMIC household-based survey conducted in Burkina Faso between March 2014 


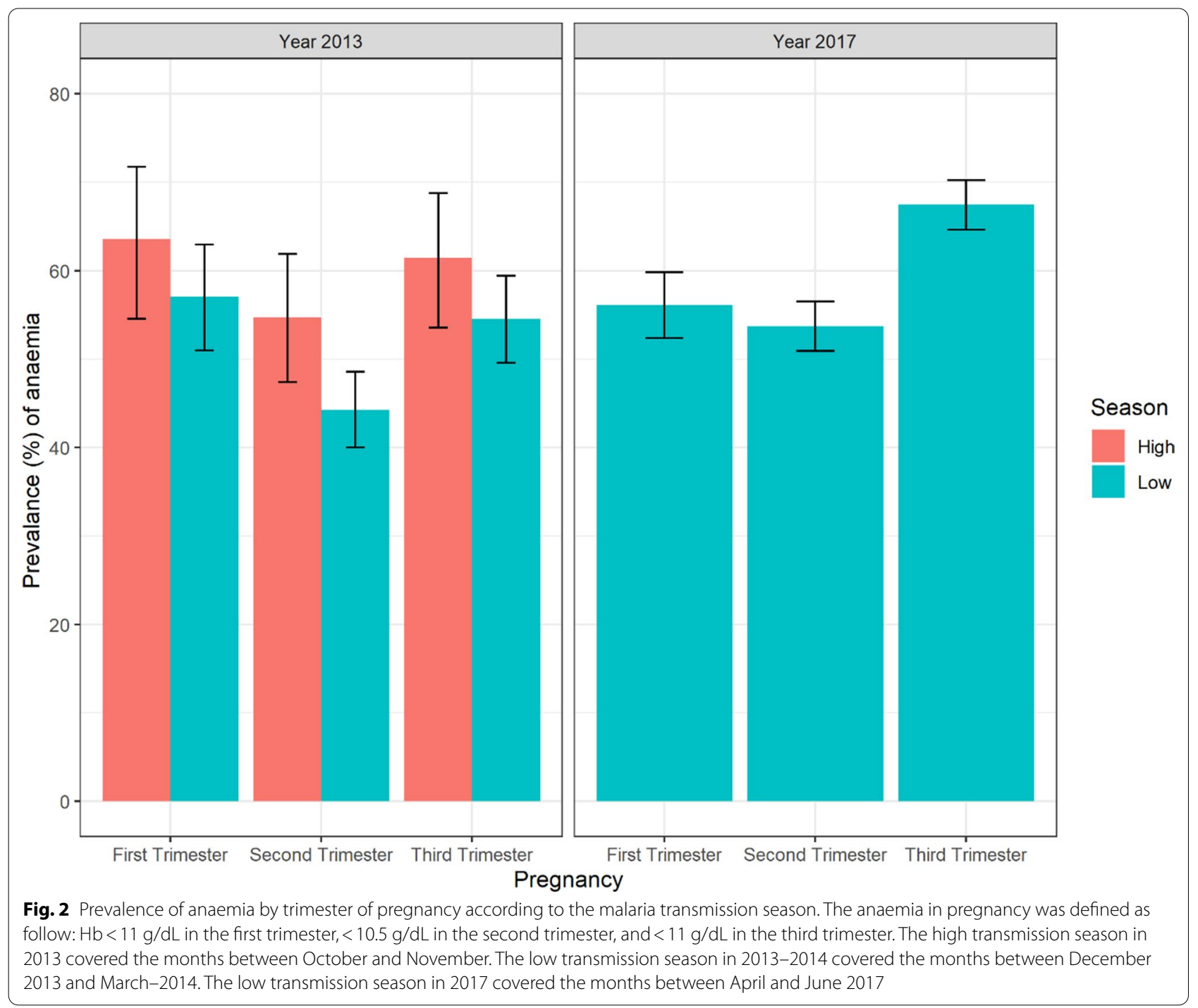

and January 2016 [29, 39]. In addition, the prevalence of asymptomatic $\mathrm{MiP}$ at the community level during the low transmission season was slightly lower compared to the prevalence of $9.1 \%$ reported from a communitybased study conducted in Ethiopia during the minor ("low") malaria transmission season [40]. Therefore, the results underline the need for maintaining effective prevention measures throughout the entire course of pregnancy. These results showed that pregnant women living in Burkina Faso (or other SSA countries) are consistently exposed to malaria risk and its harmful consequences at any time of the year. However, the highest risk of asymptomatic carriage of malaria parasites in the study seemed to occur among younger women (primi- or secundigravida), in the second and third trimester of pregnancy, and during the high malaria transmission season. These risk factors have been documented in other previous studies [10, 25-27, 33, 34, 41-43]. Thus, more efforts are needed to increase IPTp-SP coverage (i.e. monthly from the second trimester to delivery), at both the health facility level and community/household level through the community-based health workers (CHWs), in order to reduce anaemia and contribute to preventing low birth weight prevent poor pregnancy outcomes $[19,44]$. From this perspective and according to the WHO recommendations [45], several countries, including Burkina Faso, have set up strategies involving CHWs whose tasks include community-based sensitization activities, prevention measures, conducting malaria home diagnoses by RDT, and treatment of uncomplicated malaria within their respective communities $[29,46]$. 
Table 4 Potential risk factors of anemia among pregnant women surveyed at the household level in Burkina Faso in 2013/2014

\begin{tabular}{|c|c|c|c|c|c|c|}
\hline \multirow[t]{2}{*}{ Potential factors } & \multirow[t]{2}{*}{$N$} & \multirow[t]{2}{*}{ Anemia cases } & \multicolumn{2}{|c|}{ Univariate analysis } & \multicolumn{2}{|c|}{ Multivariable analysis } \\
\hline & & & PR $(95 \% \mathrm{Cl})$ & $\mathrm{p}$ & Adj. PR (95\% Cl) & $\mathrm{p}$ \\
\hline Asymptomatic malaria & & & & $<0.001^{\mathrm{a}}$ & & $<0.001^{\circ}$ \\
\hline No & 1436 & 479 & 1 & & 1 & \\
\hline Yes & 271 & 133 & $1.34(1.22-1.48)$ & & $1.31(1.18-1.44)$ & \\
\hline Age & & & & 0.21 & & 0.42 \\
\hline$\geq 30$ & 468 & 153 & 1 & & 1 & \\
\hline $20-30$ & 859 & 305 & $1.07(0.96-1.19)$ & & $1.10(0.98-1.23)$ & \\
\hline$\leq 20$ & 380 & 154 & $1.12(0.99-1.27)$ & & $1.19(1.00-1.41)$ & \\
\hline Trimester of pregnancy & & & & $<0.001^{\mathrm{a}}$ & & $<0.001^{\circ}$ \\
\hline First & 404 & 239 & 1 & & 1 & \\
\hline Second & 731 & 343 & $0.79(0.71-0.89)$ & & $0.81(0.72-0.90)$ & \\
\hline Third & 573 & 324 & $0.96(0.86-1.07)$ & & $0.97(0.87-1.08)$ & \\
\hline Parity & & & & 0.99 & & 0.28 \\
\hline Multigravida & 1039 & 360 & 1 & & 1 & \\
\hline Secundigravida & 354 & 130 & $1.00(0.89-1.12)$ & & $0.89(0.76-1.05)$ & \\
\hline Primigravida & 314 & 122 & $1.00(0.89-1.13)$ & & $0.92(0.82-1.05)$ & \\
\hline Insecticide-treated nets & & & & 0.41 & & 0.38 \\
\hline At least one & 1650 & 589 & 1 & & 1 & \\
\hline No insecticide-treated nets & 57 & 23 & $0.89(0.67-1.17)$ & & $0.87(0.66-1.15)$ & \\
\hline Education & & & & 0.56 & & 0.48 \\
\hline No education & 1696 & 608 & 1 & & 1 & \\
\hline Educated & 11 & 4 & $1.21(0.82-1.80)$ & & $1.19(0.75-1.90)$ & \\
\hline Household socioeconomic & & & & 0.75 & & 0.67 \\
\hline Middle quintile & 351 & 132 & 1 & & 1 & \\
\hline Poorest & 300 & 101 & $0.95(0.82-1.10)$ & & $0.95(0.82-1.09)$ & \\
\hline Poor & 364 & 143 & $1.03(0.90-1.17)$ & & $1.04(0.91-1.18)$ & \\
\hline Rich & 338 & 133 & $1.02(0.89-1.17)$ & & $1.02(0.89-1.17)$ & \\
\hline Richest & 354 & 103 & $0.95(0.83-1.10)$ & & $0.95(0.83-1.09)$ & \\
\hline Place of residence & & & & 0.27 & & 0.27 \\
\hline Rural & 1586 & 568 & 1 & & 1 & \\
\hline Urban & 121 & 44 & $0.90(0.74-1.09)$ & & $0.89(0.73-1.08)$ & \\
\hline Malaria season & & & & $0.001^{\mathrm{a}}$ & & $0.008^{\mathrm{a}}$ \\
\hline Low season & 1222 & 400 & 1 & & 1 & \\
\hline High season & 485 & 212 & $1.18(1.07-1.29)$ & & $1.13(1.03-1.24)$ & \\
\hline
\end{tabular}

$P R$ prevalence ratio, $A d j$. adjusted, ${ }^{a}$ significant at the 0.05 level

The study showed a high prevalence of anaemia among pregnant Burkinabe women living in their communities, though this prevalence seemed to be slightly lower compared with the prevalence among pregnant women attending health facilities as part of their ANC $[27,28]$. According to the literature, the nutritional deficiencies, particularly deficiency in iron and folic acid constitute the main causes of anaemia in pregnancy. The difference in prevalence of anaemia observed during the transmission season (especially between October-November 2014 and April June 2017) could be also explained by the food shortage period in Burkina Faso. In addition to the nutritional factors, in our context, malaria (sequestration of parasitized red blood cells in the placenta), second trimester of pregnancy, and the high malaria transmission season may not be the only causes of anaemia in pregnant women. Indeed, the causes of anaemia during pregnancy in developing countries are multifactorial and may be a result of other co-morbidities (worm infestation), complication events (including placenta previa, placental abruption), chronic diseases (HIV, sickle cell disease, and $\mathrm{TB}$ ), or nutritional deficiency (inadequate intake of iron and folic acid and/or inadequate iron + folic acid supplementation) [47-53]. Appropriate community-based 
Table 5 Potential risk factors of anaemia among pregnant women surveyed at the household level in Burkina Faso in 2017

\begin{tabular}{|c|c|c|c|c|c|c|}
\hline \multirow[t]{2}{*}{ Potential factors } & \multirow[t]{2}{*}{$\mathbf{N}$} & \multirow[t]{2}{*}{ Anaemia cases } & \multicolumn{2}{|c|}{ Univariate analysis } & \multicolumn{2}{|c|}{ Multivariable analysis } \\
\hline & & & PR $(95 \% \mathrm{Cl})$ & $\mathrm{p}$ & Adj. PR (95\% Cl) & $\mathrm{p}$ \\
\hline Asymptomatic malaria & & & & $<0.001^{\mathrm{a}}$ & & $<0.001^{\circ}$ \\
\hline No & 1714 & 770 & 1 & & 1 & \\
\hline Yes & 117 & 83 & $1.37(1.27-1.48)$ & & $1.47(1.34-1.60)$ & \\
\hline Age & & & & 0.60 & & 0.56 \\
\hline$\geq 30$ & 623 & 290 & 1 & & 1 & \\
\hline $20-30$ & 933 & 426 & $0.97(0.90-1.05)$ & & $0.95(0.88-1.03)$ & \\
\hline$\leq 20$ & 275 & 137 & $1.02(0.92-1.13)$ & & $0.93(0.81-1.07)$ & \\
\hline Trimester of pregnancy & & & & $<0.001^{\mathrm{a}}$ & & $<0.001^{\circ}$ \\
\hline First & 426 & 236 & 1 & & 1 & \\
\hline Second & 709 & 432 & $1.10(0.99-1.22)$ & & $1.11(1.00-1.23)$ & \\
\hline Third & 697 & 523 & $1.35(1.23-1.49)$ & & $1.39(1.27-1.53)$ & \\
\hline Parity & & & & 0.64 & & 0.94 \\
\hline Multigravida & 1325 & 608 & 1 & & 1 & \\
\hline Secundigravida & 310 & 140 & $1.05(0.94-1.16)$ & & $1.02(0.89-1.18)$ & \\
\hline Primigravida & 196 & 105 & $1.03(0.94-1.12)$ & & $1.02(0.93-1.13)$ & \\
\hline Insecticide-treated nets & & & & 0.39 & & 0.54 \\
\hline At least one & 1762 & 817 & 1 & & 1 & \\
\hline No insecticide-treated nets & 69 & 36 & $1.07(0.91-1.26)$ & & $1.02(0.87-1.21)$ & \\
\hline Education & & & & 0.75 & & 0.97 \\
\hline No education & 1755 & 819 & 1 & & 1 & \\
\hline Educated & 76 & 34 & $1.01(0.86-1.26)$ & & $1.00(0.85-1.18)$ & \\
\hline Household socioeconomic & & & & $0.022^{\mathrm{a}}$ & & 0.06 \\
\hline Middle quintile & 360 & 161 & 1 & & 1 & \\
\hline Poorest & 334 & 182 & $1.12(1.01-1.23)$ & & $1.10(0.99-1.21)$ & \\
\hline Poor & 363 & 169 & $0.97(0.87-1.08)$ & & $0.97(0.87-1.08)$ & \\
\hline Rich & 375 & 180 & $1.02(0.92-1.13)$ & & $1.01(0.91-1.13)$ & \\
\hline Richest & 399 & 161 & $0.95(0.85-1.06)$ & & $0.96(0.86-1.07)$ & \\
\hline Place of residence & & & & 0.43 & & 0.32 \\
\hline Rural & 1685 & 789 & 1 & & 1 & \\
\hline Urban & 146 & 64 & $0.95(0.83-1.08)$ & & $0.94(0.83-1.06)$ & \\
\hline
\end{tabular}

$P R$ prevalence ratio, $A d j$. adjusted, ${ }^{a}$ significant at the 0.05 level

strategies to prevent anaemia in pregnancy can help to significantly reduce the occurrence of maternal anaemia and, thereby, avoid progression to fatal outcomes. In this respect, the capacity of $\mathrm{CHWs}$ should be strengthened to allow them to carry out targeted sensitization of the risk factors leading to anaemia, ensure effective adherence to preventive measures among the community, detect clinical signs of anaemia (pallor, fatigue, bleeding), and direct people to a health centre for appropriate clinical management (such as administering of a double dose of iron) [54].

Although the findings of this study provide an overview of the extent of asymptomatic malaria and anaemia in pregnant women at the community level, both during the high and the low transmission seasons in Burkina Faso, some potential limitations need to be considered. First, asymptomatic carriage of malaria parasites was defined by using a malaria RDT, which could lead to underestimation (due to false negatives) or overestimation (false positives) of the true prevalence. False negatives from the malaria RDT may be due to the detection threshold of the test (around 200 parasites/ $\mu \mathrm{L}$ ) [55]. Regarding the false negative results, some studies found that more than half of all false negatives were in cases of parasitemia in which the detected antigen was under the detection threshold (i.e., lower density). False positives could be due to prolonged antigen circulation following clearance of malaria parasites. Indeed, it was shown that HRP2 antigens can persist in the bloodstream of pregnant women for up to four weeks after successful treatment [56]. However, 
in high-transmission areas such as Burkina Faso, HRP2 RDT could be a useful tool for malaria diagnosis, since previous studies found its performance was better than that of microscopy when used in pregnant women [31]. Second, the cross-sectional study design did not allow us to determine cause and effect. Third, the two survey periods (not overlapping) did not allow us to compare outcomes over time, although this was not in the scope of this study. Fourth, the estimation of the gestational age through mainly the recall of last menstrual cycle could introduce classification bias in the estimation of trimester of pregnancy. The absence of indicator related to the use of ITNs by the pregnant women (a good proxy of protection conferred by bed nets) did not allow us to raise the effect of protection conferred by ITNs. In addition, information regarding the number of doses taken by pregnant woman was not available. However, since the IPTp-SP is planned to be systematically given to the pregnant women after the first trimester of pregnancy, regardless the month of the year, suggests that there was not difference related to season. Therefore, the absence of any benefit of bed nets ownership should be interpreted with caution.

\section{Conclusion}

This study showed a high prevalence of both asymptomatic malaria and anaemia during pregnancy, and it indicated the risks increased dramatically during the high transmission season. Thus, infected anaemic (or non-anaemic) women, apart from consequences to their unborn babies (being considered as reservoirs of parasites that may promote mother-to-child transmission), represent an important parasite reservoir contributing to the cycle of malaria transmission in the community. In order to mitigate the harmful effects of asymptomatic carriage of malaria parasites and anaemia for both the mother and her fetus, health programmes aimed at increasing the number of pregnant women coming into contact with health workers should be at least maintained or strengthened. Therefore, more efforts are needed to increase IPTp-SP coverage, at both the health facility and community/household level, to prevent poor pregnancy outcomes $[19,44]$. This could be implemented by strengthening the activities of community-based health workers (regular screening for malaria and anaemia in villages and households) in order to reduce the progression of asymptomatic cases to clinical, or even severe cases before pregnant women can reach the health centres for ANC.

\section{Abbreviations}

Adj.: Adjusted; ANC: Antenatal care; CAPI: Computer-assisted personal interview; CHW: Community-based health workers; Cl: Confidence intervals; GEE:
Generalized estimating equations; HIV: Human immunodeficiency viruses; HRPII: Histidine-rich protein II; IPTp: Intermittent preventive treatment during pregnancy; MiP: Malaria infection in pregnancy; PR: Prevalence ratios; RDT: Rapid diagnostic tests; SP: Sulfadoxine-pyrimethamine; SSA: Sub-Saharan African; TB: Tuberculosis; WHO: World Health Organization.

\section{Acknowledgements}

The authors are grateful to the research and data collection team engaged at Centre Muraz. study.

Our gratitude also goes to the pregnant women who participated in this

T.R is funded through a travel grant from ARES-CCD. SS research is supported by the postdoctoral fellowship from the Fonds de recherche du Québec Santé (FRQS).

\section{Authors' contributions}

SS and FKS designed the study protocol. RT and SS performed the statistical analysis and draft the manuscript. HH performed coordination of field activities and supervised data collection. TR, SS,MO, HH, HT, and FKS contributed to the manuscript by making substantial intellectual contributions. All authors read and approved the final manuscript.

\section{Funding}

T.R is funded through a travel Grant from ARES-CCD.

Availability of data and materials

The dataset containing individual and household level records is available at the Centre MURAZ in Burkina Faso.

\section{Declarations}

Ethics approval and consent to participate

The main research protocol from which the present study extracted the data was approved by the National Ethics Committee for Health Research of the Burkina Faso Ministry of Health. Authorization to work in the selected health regions was obtained from the Burkina Faso Ministry of Health. Informed consent was obtained from the participants or guardians before performing RDT and haemoglobin tests.

Consent for publication

Not applicable.

\section{Competing interests}

The authors declare that they have no competing interests.

\section{Author details}

${ }^{1}$ Clinical Research Unit of Nanoro, Institut de Recherche en Sciences de La Santé, Centre National de La Recherche Scientifique Et Technologique, 42, Avenue Kumda-Yoore, BP 218 Ouagadougou CMS 11, Ouagadougou, Burkina Faso. ${ }^{2}$ Centre de Recherche en Epidémiologie, Biostatistique Et Recherche Clinique, Ecole de Santé Publique, Université Libre de Bruxelles (ULB), Route de Lennik, 808, 1070 Bruxelles, Belgium. ${ }^{3}$ Evaluation Platform On Obesity Prevention, Quebec Heart and Lung Institute, Quebec G1V 4G5, Canada. ${ }^{4}$ Centre for Research On Planning and Development (CRAD), Laval University, Quebec G1V 0A6, Canada. ${ }^{5}$ Institut National de La Statistique Et de La Démographie [INSD], 01 BP 374, Ouagadougou 01, Ouagadougou, Burkina Faso. ${ }^{6}$ Intitut National de Santé Publique (INSP), Centre Muraz, Bobo-Dioulasso, Burkina Faso. ${ }^{7}$ Institut de Recherche en Sciences de La Santé, Centre National de La Recherche Scientifique Et Technologique, 42, Avenue Kumda-Yoore, BP 218 Ouagadougou CMS 11, Ouagadougou, Burkina Faso.

Received: 13 November 2020 Accepted: 15 March 2021

Published online: 01 May 2021

References

1. Schantz-Dunn J, Nour NM. Malaria and pregnancy: a global health perspective. Rev Obstet Gynecol. 2009;2:186-92. 
2. van Geertruyden J-P, Thomas F, Erhart A, D'Alessandro U. The contribution of malaria in pregnancy to perinatal mortality. Am J Trop Med Hyg. 2004;71:35-40

3. Schwetz J, Peel E. Congenital malaria and placental infections amongst the Negroes of central Africa. Trans R Soc Trop Med Hyg. 1934;28:167-74.

4. Madanitsa M, Kalilani L, Mwapasa V, van Eijk AM, Khairallah C, Ali D, et al. Scheduled intermittent screening with rapid diagnostic tests and treatment with dihydroartemisinin-piperaquine versus intermittent preventive therapy with sulfadoxine-pyrimethamine for malaria in pregnancy in Malawi: an open-label randomized controlled trial. PLoS Med. 2016;13:e1002124.

5. Menendez C, Ordi J, Ismail MR, Ventura PJ, Aponte JJ, Kahigwa E, et al. The impact of placental malaria on gestational age and birth weight. J Infect Dis. 2000;181:1740-5.

6. Steketee RW, Nahlen BL, Parise ME, Menendez C. The burden of malaria in pregnancy in malaria-endemic areas. Am J Trop Med Hyg. 2001;64:28-35.

7. Shulman CE, Marshall T, Dorman EK, Bulmer JN, Cutts F, Peshu N, et al. Malaria in pregnancy: adverse effects on haemoglobin levels and birthweight in primigravidae and multigravidae. Trop Med Int Health. 2001:6:770-8

8. Uneke CJ, Sunday-Adeoye I, Iyare FE, Ugwuja El, Duhlinska DD. Impact of maternal Plasmodium falciparum malaria and haematological parameters on pregnancy and its outcome in southeastern Nigeria. J Vector Borne Dis. 2007:44:285-90.

9. Natama HM, Ouedraogo DF, Sorgho H, Rovira-Vallbona E, Serra-Casas E, Somé MA, et al. Diagnosing congenital malaria in a high-transmission setting: clinical relevance and usefulness of P. falciparum HRP2-based testing. Sci Rep. 2017;7:2080.

10. Berry I, Walker P, Tagbor H, Bojang K, Coulibaly SO, Kayentao K, et al. Seasonal dynamics of malaria in pregnancy in West Africa: evidence for carriage of infections acquired before pregnancy until first contact with antenatal care. Am J Trop Med Hyg. 2018;98:534-42.

11. Sule-Odu AO, Ogunledun A, Olatunji AO. Impact of asymptomatic maternal malaria parasitaemia at parturition on perinatal outcome. J Obstet Gynaecol (Lahore). 2002;22:25-8.

12. Anorlu RI, Odum CU, Essien EE. Asymptomatic malaria parasitaemia in pregnant women at booking in a primary health care facility in a periurban community in Lagos. Nigeria Afr J Med Med Sci. 2001;30(Suppl):39-41.

13. Matangila JR, Lufuluabo J, Ibalanky AL, Inocêncio da Luz RA, Lutumba P, Van Geertruyden J-P. Asymptomatic Plasmodium falciparum infection is associated with anaemia in pregnancy and can be more cost-effectively detected by rapid diagnostic test than by microscopy in Kinshasa, Democratic Republic of the Congo. Malar J. 2014;13:132.

14. Nwagha UI, Ugwu VO, Nwagha TU, Anyaehie BU. Asymptomatic Plasmodium parasitaemia in pregnant Nigerian women: almost a decade after Roll Back Malaria. Trans R Soc Trop Med Hyg. 2009;103:16-20.

15. WHO. Malaria surveillance, monitoring and evaluation: a reference manual. Geneva: World Health Organization; 2018. https://who.int/iris/ handle/10665/272284

16. Geiger C, Compaore G, Coulibaly B, Sie A, Dittmer M, Sanchez C, et al. Substantial increase in mutations in the genes pfdhfr and pfdhps puts sulphadoxine-pyrimethamine-based intermittent preventive treatment for malaria at risk in Burkina Faso. Trop Med Int Health. 2014;19:690-7.

17. Mockenhaupt FP, Bedu-Addo G, Eggelte TA, Hommerich L, Holmberg $V$, von Oertzen C, et al. Rapid increase in the prevalence of sulfadoxinepyrimethamine resistance among Plasmodium falciparum isolated from pregnant women in Ghana. J Infect Dis. 2008;198:1545-9.

18. Rouamba T, Samadoulougou S, Tinto H, Alegana VA, Kirakoya F. Spatial and spatio-temporal epidemiology severe-malaria infection and its outcomes among pregnant women in Burkina Faso health-districts : hierarchical Bayesian space-time models applied to routinely-collected data from 2013 to 2018. Spat Spatiotemporal Epidemiol. 2020;33:100333.

19. Tagbor H, Bruce J, Agbo M, Greenwood B, Chandramohan D. Intermittent screening and treatment versus intermittent preventive treatment of malaria in pregnancy: a randomised controlled non-inferiority trial. PLoS ONE. 2010;5:e14425

20. Roh ME, ter Kuile FO, Rerolle F, Glymour MM, Shiboski S, Gosling R, et al. Overall, anti-malarial, and non-malarial effect of intermittent preventive treatment during pregnancy with sulfadoxine-pyrimethamine on birthweight: a mediation analysis. Lancet Glob Health. 2020;8:e942-53.
21. Okell LC, Griffin JT, Roper C. Mapping sulphadoxine-pyrimethamineresistant Plasmodium falciparum malaria in infected humans and in parasite populations in Africa. Sci Rep. 2017;7:7389.

22. van Eijk AM, Larsen DA, Kayentao K, Koshy G, Slaughter DEC, Roper C, et al. Effect of Plasmodium falciparum sulfadoxine-pyrimethamine resistance on the effectiveness of intermittent preventive therapy for malaria in pregnancy in Africa: a systematic review and meta-analysis. Lancet Infect Dis. 2019;19:546-56.

23. Kayentao K, Kodio M, Newman RD, Maiga H, Doumtabe D, Ongoiba A et al. Comparison of intermittent preventive treatment with chemoprophylaxis for the prevention of malaria during pregnancy in Mali. J Infect Dis. 2005;191:109-16.

24. Yaméogo TM, Kyelem CG, Bamba S, Savadogo LB, Sombié I, Traoré AZ, et al. Chemin de soin des cas présomptifs de paludisme admis dans un hôpital de district au Burkina Faso. Med Sante Trop. 2014;24:301-6.

25. Cisse M, Sangare I, Lougue G, Bamba S, Bayane D, Guiguemde RT. Prevalence and risk factors for Plasmodium falciparum malaria in pregnant women attending antenatal clinic in Bobo-Dioulasso (Burkina Faso). BMC Infect Dis. 2014;14:631.

26. Ouédraogo CMR, Nébié G, Sawadogo L, Rouamba G, Ouédraogo A, Lankoandé J. Étude des facteurs favorisant la survenue du paludisme à Plasmodium falciparum chez les femmes enceintes dans le district sanitaire de Bogodogo à Ouagadougou, Burkina Faso. J Gynecol Obstet Biol Reprod. 2011;40:529-34.

27. Tahita MC, Tinto H, Menten J, Ouedraogo JB, Guiguemde RT, Van Geertruyden JP, et al. Clinical signs and symptoms cannot reliably predict Plasmodium falciparum malaria infection in pregnant women living in an area of high seasonal transmission. Malar J. 2013;12:464.

28. Douamba Z, Bisseye C, Djigma FW, Compaoré TR, Bazie VJT, Pietra V, et al. Asymptomatic malaria correlates with anaemia in pregnant women at Ouagadougou, Burkina Faso. J Biomed Biotechnol. 2012;2012:198317.

29. Ruizendaal E, Schallig HDFH, Scott S, Traore-Coulibaly M, Bradley J, Lompo $\mathrm{P}$, et al. Evaluation of malaria screening during pregnancy with rapid diagnostic tests performed by community health workers in Burkina Faso. Am J Trop Med Hyg. 2017:97:1190-7.

30. Burkina Faso-Health results-based financing impact evaluation 2013. Household Baseline Survey. https://microdata.worldbank.org/index.php/ catalog/2762. Accessed 30 Sept 2020

31. Kattenberg JH, Tahita CM, Versteeg IAJ, Tinto H, Traoré-Coulibaly M, D'Alessandro $\mathrm{U}$, et al. Evaluation of antigen detection tests, microscopy, and polymerase chain reaction for diagnosis of malaria in peripheral blood in asymptomatic pregnant women in Nanoro, Burkina Faso. Am J Trop Med Hyg. 2012;87:251-6.

32. Di Renzo GC, Spano F, Giardina I, Brillo E, Clerici G, Roura LC. Iron deficiency anemia in pregnancy. Women's Health (Lond). 2015;11:891-900.

33. Coulibaly SO, Gies S, D'Alessandro U. Malaria burden among pregnant women living in the rural district of Boromo, Burkina Faso. Am J Trop Med Hyg. 2007;77:56-60.

34. Valea I, Tinto H, Drabo MK, Huybregts L, Sorgho H, Ouedraogo J-B, et al. An analysis of timing and frequency of malaria infection during pregnancy in relation to the risk of low birth weight, anaemia and perinatal mortality in Burkina Faso. Malar J. 2012;11:71.

35. Rouamba T, Samadoulougou S, Tinto H, Alegana VA, Kirakoya-Samadoulougou F. Bayesian Spatiotemporal modeling of routinely collected data to assess the effect of health programs in malaria incidence during pregnancy in Burkina Faso. Sci Rep. 2020;10:2618.

36. Fox J, Monette G. Generalized collinearity diagnostics. JASA. 1992:87:178-83.

37. Brabin BJ. An analysis of malaria in pregnancy in Africa. Bull World Health Organ. 1983;61:1005-16.

38. Worrall E, Morel C, Yeung S, Borghi J, Webster J, Hill J, et al. The economics of malaria in pregnancy-a review of the evidence and research priorities. Lancet Infect Dis. 2007;7:156-68.

39. Scott $S$, Mens PF, Tinto $H$, Nahum A, Ruizendaal E, Pagnoni F, et al. Community-based scheduled screening and treatment of malaria in pregnancy for improved maternal and infant health in The Gambia, Burkina Faso and Benin : study protocol for a randomized controlled trial. Trials. 2014;15:340.

40. Nega D, Dana D, Tefera T, Eshetu T. Prevalence and predictors of asymptomatic malaria parasitemia among pregnant women in the rural surroundings of Arbaminch Town, South Ethiopia. PLoS ONE. 2015;10:e0123630. 
41. Kassa GM, Muche AA, Berhe AK, Fekadu GA. Prevalence and determinants of anemia among pregnant women in Ethiopia; a systematic review and meta-analysis. BMC Hematol. 2017;17:17.

42. Thompson JM, Eick SM, Dailey C, Dale AP, Mehta M, Nair A, et al. Relationship between pregnancy-associated malaria and adverse pregnancy outcomes: a systematic review and meta-analysis. J Trop Pediatr. 2020;66:327-38

43. Eisele TP, Larsen DA, Anglewicz PA, Keating J, Yukich J, Bennett A, et al. Malaria prevention in pregnancy, birthweight, and neonatal mortality: a meta-analysis of 32 national cross-sectional datasets in Africa. Lancet Infect Dis. 2012;12:942-9.

44. Cosmic Consortium. Community-based malaria screening and treatment for pregnant women receiving standard intermittent preventive treatment with sulfadoxine-pyrimethamine: a multicenter (The Gambia Burkina Faso, and Benin) cluster-randomized controlled trial. Clin Infect Dis. 2018;68:586-96.

45. World Health Organization. Global Technical Strategy for Malaria 20162030. Geneva: Global Malaria Programme, World Health Organization; 2015. http://apps.who.int/iris/bitstream/handle/10665/176712/97892 41564991_eng.pdf;jsessionid=66E6DA665C88369AF0BA3A99E8525283? sequence $=1$.

46. Ministère de la santé/Direction de la Promotion de la Santé. Plan stratégique de promotion de la sante 2015-2019. Ouagadougou, Burkina Faso; 2014.

47. Jain D, Atmapoojya P, Colah R, Lodha P. Sickle cell disease and pregnancy. Mediterr J Hematol Infect Dis. 2019;11:e2019040.

48. Rogers DT, Molokie R. Sickle cell disease in pregnancy. Obstet Gynecol Clin North Am. 2010;37:223-37.

49. Dicko A, Mantel C, Thera MA, Doumbia S, Diallo M, Diakité M, et al. Risk factors for malaria infection and anemia for pregnant women in the Sahel area of Bandiagara. Mali Acta Trop. 2003;89:17-23.
50. Ononge S, Campbell O, Mirembe F. Haemoglobin status and predictors of anaemia among pregnant women in Mpigi, Uganda. BMC Res Notes. 2014;7:712.

51. Haider BA, Olofin I, Wang M, Spiegelman D, Ezzati M, Fawzi WW. Anaemia, prenatal iron use, and risk of adverse pregnancy outcomes: systematic review and meta-analysis. BMJ. 2013;346:f3443.

52. Orish VN, Onyeabor OS, Boampong JN, Acquah S, Sanyaolu AO, Iriemenam NC. The effects of malaria and HIV co-infection on hemoglobin levels among pregnant women in Sekondi-Takoradi. Ghana Int J Gynecol Obstet. 2013;120:236-9.

53. Brooker S, Hotez PJ, Bundy DAP. Hookworm-related anaemia among pregnant women: a systematic review. PLoS Negl Trop Dis. 2008;2:e291.

54. WHO. Daily iron and folic acid supplementation in pregnant women. Geneva: World Health Organization; 2012. http://www.who.int/nutri tion/publications/micronutrients/guidelines/daily_ifa_supp_pregnant_ women/en/.

55. WHO. Malaria rapid diagnostic test performance: results of WHO product testing of malaria RDTs: round 8 (2016-2018). Geneva: World Health Organization; 2018.

56. Kattenberg JH, Tahita CM, Versteeg IAJ, Tinto H, Traoré-Coulibaly M, Schallig HDFH, et al. Antigen persistence of rapid diagnostic tests in pregnant women in Nanoro, Burkina Faso, and the implications for the diagnosis of malaria in pregnancy. Trop Med Int Health. 2012;17:550-7.

\section{Publisher's Note}

Springer Nature remains neutral with regard to jurisdictional claims in published maps and institutional affiliations.
Ready to submit your research? Choose BMC and benefit from:

- fast, convenient online submission

- thorough peer review by experienced researchers in your field

- rapid publication on acceptance

- support for research data, including large and complex data types

- gold Open Access which fosters wider collaboration and increased citations

- maximum visibility for your research: over 100M website views per year

At BMC, research is always in progress.

Learn more biomedcentral.com/submissions 